\title{
Cutaneous Manifestations In Chronic Renal Failure Patients
}

\section{Shakya N B ${ }^{1}$, Rajbhandari S L², Sharma $A^{3}$, Deo RK ${ }^{4}$ J ha SM ${ }^{5}$}

${ }^{1}$ Dr. Nabin Bhakta Shakya,Dermato-venereologist, ${ }^{2}$ Dr. Sudersan Lal R ajbhandari, Dermato-venereologist, Department of Dermatology and Venereology, ${ }^{3}$ Dr. Arun Sharma, Consultant Nephrologist, ${ }^{3}$ Dr Rajeeb Kumar Deo, Consultant Internal Medicine, Department of Medicine, ${ }^{5}$ Dr. Sagar Mani J ha, Dermato-venereologist and Head of the Department, Department of Dermatology and Venereology, Shree Birendra Hospital, Chhauni, Kathmandu, Nepal.

\begin{abstract}
Introduction: Chronic renal failure is a pathophysiologic process with multiple etiologies, resulting in the inexorable attrition of nephron number and function, and frequently leading to end stage renal disease. There are various cutaneous changes in chronic renal failure.

Objectives: To observe the cutaneous manifestation in chronic renal failure and find out any difference in occurrence of cutaneous manifestation with modality of treatment of CR F.

Methods: The study was conducted in 50 (fifty) adult patients with chronic renal failure and another 50 (fifty) patients with similar age admitted with other renal diseases but not suffering from chronic renal failure as control to facilitate comparison were considered in the Department of Dermatology and Venereology and the Department of Medicine, Shree Birendra Hospital, Chhauni from September 2008 to J une 2010.

Results: A significant occurrence of pruritus, xerosis and pallor in CRF patients; the highest being pruritus followed by xerosis and pallor. Occurrence of pruritus was found to be more in HD patients $(68 \%)$ than in IPD patients (38\%). No correlation was found between ages, sex, and duration of dialys is with complaint of pruritus. S kin xerosis is considered an important factor contributing or initiating pruritus.
\end{abstract}

Conclusion: Pruritus is the commonest cutaneous manifestation of chronic renal failure.

\section{Introduction}

The skin is the most visible and easily accessible organ of the body. For an astute clinician, the skin may function as an important diagnostic window to disease affecting internal organ. This is especially true for the renal system ${ }^{1-4}$

Chronic renal failure is a pathophysiologic process with multiple etiologies, resulting in the inexorable attrition of nephron number and function, and frequently leading to end stage renal disease (ESRD) ${ }^{5-}$ 6.

ESRD represent a clinical state or condition in which there has been an irreversible loss of endogenous renal function, of a degree sufficient to render the patients permanently dependent upon renal replacement therapy (dialysis or transplantation) in order to avoid life threatening uremia ${ }^{70}$.

Uremia is the clinical and laboratory syndrome, reflecting dysfunction of all organ systems as a result of untreated acute or chronic renal failure.

For our study purpose cutaneous manifestations of chronic renal failure may be divided into 3 general categories including:

1. Cutaneous manifestations in patients on hemodialysis (HD).

2. Cutaneous manifestations in patients on intermittent peritoneal dialysis (IPD).

Address for correspondence: docnabin@yahoo.com
3. Cutaneous manifestations in patients on medical treatment.

Cutaneous Changes Associated With CRF:

Xerosis

Pallor

A sallow yellowish cast to the skin

Diffuse hyperpigmentation

Half and half nails

Eextensive eccymoes

Calcinosis cutis due to secondary hyperparathyroidism

Uremic frost

Lichen simplex chronicus

Prurigo nodularis

Xanthomas

Uremic Neuropathy

Cutaneous ischaemic ulceration ${ }^{7-13}$ 
Cutaneous Manifestations In Patients On Dialysis (Haemodialysis And Peritoneal Dialysis):

Contact dermatitis at site of A-V fistula or peritoneal cannnula

Bullous disease of dialysis

Acquired perforating disease of hemodialysis

Arterialization at $\mathrm{A}-\mathrm{V}$ fistula site

Edema and postiflammatory hyperpigmentation in the arm of $A-V$ fistula

P riritus

Xerosis

Aalteration in skin pigmentation

Half and half nails

Calcinosis cutis

Calciphylaxis

Kyrle's disease

Gynaecomeastia

\section{Objectives}

1. To observe the cutaneous manifestation in chronic renal failure.

2. To find out any difference in occurrence of

\section{Observation and results}

Table I: Distribution of The CRF And Non CRF Renal $P$ atients By Age:

\begin{tabular}{|c|c|c|c|c|c|}
\hline \multicolumn{2}{|c|}{ Age group } & \multicolumn{4}{|c|}{ CRF $(n=50) \quad$ Non CRF $(n=50)$} \\
\hline & & Freq & Percent & Freq & Percent \\
\hline 1 & $<20$ year & 8 & 16 & 8 & 16 \\
\hline 2 & 21- 30 year & 6 & 12 & 7 & 14 \\
\hline 3 & 31- 40 year & 16 & 12 & 7 & 14 \\
\hline 4 & 41- 50 Year & 8 & 16 & 16 & 32 \\
\hline 5 & $>50$ Year & 12 & 24 & 10 & 20 \\
\hline & Total & 50 & 100 & 50 & 100 \\
\hline
\end{tabular}

Table II: Distribution Of Patients By Sex:

\begin{tabular}{|l|l|l|}
\hline & Male & Female \\
\hline CRF & $26(52 \%)$ & $\mathbf{2 4 ( 4 8 \% )}$ \\
\hline Non CRF & $27(54 \%)$ & $\mathbf{2 3 ( 4 6 \% )}$ \\
\hline Total & $\mathbf{4 9 ( 4 9 \% )}$ & $\mathbf{5 1 ( 5 1 \% )}$ \\
\hline
\end{tabular}

cutaneous manifestation with modality of treatment of CRF.

\section{Methods}

The study was conducted in 50 (fifty) adult patients with chronic renal failure in the Department of Dermatology and Venereology and the Department of Medicine, Shree Birendra Hospital, Chhauni from September 2008 to J une 2010.

Another 50 (fifty) patients with similar age admitted with other renal diseases but not suffering from chronic renal failure were considered as control to facilitate comparison.

\section{Inclusion criteria:}

1. Patients of both sexes with CRF receiving HD, IPD and medical treatment.

2. Patients with kidney diseases but not suffering from renal failure as control.

\section{Exclusion criteria:}

1. Patients who have recovered from CRF or who have received renal transplantation.

2. Patients with renal diseases with cutaneous manifestation as part of features of primary disease itself and not necessarily associated with CRF e.g. SLE, PSS, Amyloidosis etc.

3. Any previous history of pruritus or skin disease not relevant with the occurrence of CRF.

Table III: Cutaneous Manifestations In Both (CRF And Non CRF) Groups Of Patients:

\begin{tabular}{|l|l|l|}
\hline & CRF $(\mathbf{n = 5 0 )}$ & Non CRF $(\mathbf{n}=\mathbf{5 0 )}$ \\
\hline 1. Pruritus & $30(60 \%)$ & $06(12 \%)$ \\
\hline 2. Xerosis & $20(40 \%)$ & $02(04 \%)$ \\
\hline 3. Pallor & $20(40 \%)$ & $16(32 \%)$ \\
\hline 4. Hyperpigmentation & $04(08 \%)$ & Nil \\
\hline 5. Half and half nail & $06(12 \%)$ & Nil \\
\hline 6.Other manifestation & Nil & Nil \\
\hline
\end{tabular}

Table IV: Overall Cutaneous Manifestation in Patients Suffering From CRF :

\begin{tabular}{|l|l|l|l|l|}
\hline $\begin{array}{l}\text { S I } \\
\text { No }\end{array}$ & Manifestation & HD (n=35) & IPD (n=13) & $\begin{array}{l}\text { CRF(No dialysis) } \\
(\mathbf{n}=\mathbf{0 2})\end{array}$ \\
\hline $\mathbf{1 .}$ & Pruritus & $24(68.6 \%)$ & $5(38.5 \%)$ & $1(50 \%)$ \\
\hline 2. & Xerosis & $15(42.8 \%)$ & $5(38.5 \%)$ & 0 \\
\hline 3. & Pallor & $14(40 \%)$ & $6(46.2 \%)$ & 0 \\
\hline 4. & Hyper pigmentation & $03(8.6 \%)$ & $1(7.7 \%)$ & 0 \\
\hline $\mathbf{5 .}$ & Half \& half nail & $06(17.1 \%)$ & 0 & 0 \\
\hline
\end{tabular}


Table V: Distribution of P ruritus:

\begin{tabular}{|l|l|l|}
\hline & \multicolumn{2}{|c|}{ Pruritus } \\
\hline & Present & Absent \\
\hline CRF $(\mathbf{n = 5 0 )}$ & $30(60 \%)$ & $20(40 \%)$ \\
\hline Non CRF $(\mathbf{n = 5 0 )}$ & $06(12 \%)$ & $44(88 \%)$ \\
\hline Total & $\mathbf{3 6 ( 3 6 \% )}$ & $\mathbf{6 4 ( 6 4 \% )}$ \\
\hline
\end{tabular}

Table VI: Distribution of Xerosis:

\begin{tabular}{|l|l|l|}
\hline & \multicolumn{2}{|c|}{ Xerosis } \\
\hline & Present & Absent \\
\hline CRF $(\mathbf{n = 5 0 )}$ & $20(40 \%)$ & $30(60 \%)$ \\
\hline Non CRF $(\mathbf{n = 5 0 )}$ & $02(4 \%)$ & $48(96 \%)$ \\
\hline Total & $\mathbf{2 2 ( 2 2 \% )}$ & $\mathbf{7 8 ( 7 8 \% )}$ \\
\hline
\end{tabular}

Table VIl: Distribution of Pallor:

\begin{tabular}{|l|l|l|}
\hline & \multicolumn{2}{|c|}{ Pallor } \\
\hline & Present & Absent \\
\hline CRF $(\mathbf{n = 5 0 )}$ & $20(40 \%)$ & $30(60 \%)$ \\
\hline Non CRF $(\mathbf{n = 5 0 )}$ & $16(32 \%)$ & $34(68 \%)$ \\
\hline Total & $\mathbf{3 6 ( 3 6 \% )}$ & $\mathbf{6 4 ( 6 4 \% )}$ \\
\hline
\end{tabular}

Table VIII: Distribution of Hyperpigmentation:

\begin{tabular}{|l|l|c|}
\hline & \multicolumn{2}{|c|}{ Hyperpigmentation } \\
\hline & Present & Absent \\
\hline CRF $(\mathbf{n = 5 0 )}$ & $04(08 \%)$ & $46(92 \%)$ \\
\hline Non CRF $(\mathbf{n = 5 0 )}$ & $0(0 \%)$ & $50(100 \%)$ \\
\hline Total & $\mathbf{0 4}(\mathbf{0 4 \% )}$ & $\mathbf{9 6}(\mathbf{9 6 \% )}$ \\
\hline
\end{tabular}

Table IX: Distribution of Half and half nail:

\begin{tabular}{|l|l|l|}
\hline & \multicolumn{2}{|c|}{ Half and half nail } \\
\hline & Present & Absent \\
\hline CRF $(\mathbf{n = 5 0 )}$ & $6(12 \%)$ & $44(88 \%)$ \\
\hline Non CRF $(\mathbf{n = 5 0 )}$ & $0(0 \%)$ & $50(100 \%)$ \\
\hline Total & $\mathbf{6 ( 6 \% )}$ & $\mathbf{9 4}(\mathbf{9 4} \%)$ \\
\hline
\end{tabular}

\section{Discussion}

Among the study cases of 50 patients, a total number of 80 cutaneous manifestations were noted. The results of this showed a significant occurrence of pruritus, xerosis and pallor in CRF patients; the highest being pruritus followed by xerosis and pallor.

Pallor was noted in 30 patients $(60 \%)$. O ccurrence of pruritus was found to be more in HD patients $(68 \%)$ than in IPD patients (38\%). No correlation was found between ages, sex, and duration of dialysis with complaint of pruritus.

Skin xerosis is considered an important factor contributing or initiating pruritus. In our study it was found that, xerosis and pruritus co-existed in 17 patients $(34 \%)$. Xerosis was noted in 20 patients $(40 \%)$ out of fifty CRF cases. Xerosis was not related with duration of CRF or type of dialysis.

Pallor was noted in 20 patients. All the cases were secondary to anaemia.

Hyperpigmentation was noted only in four (8\%) patients. In two patients the pigmentation was generalized and in the other two it was more accentuated in exposed parts, especially on faces.

The study shows half and half nail in only six patients $(12 \%)$ and this feature only noticed in finger nails not in toe nails.

Arterialization of the limb where A-V fistula was made was noted in 23 cases out of 35 HD patients.

\section{Conclusion}

Pruritus is the commonest cutaneous manifestation of chronic renal failure.

\section{References}

1. Picó MR, Lugo-Somolinos A, Sánchez J L, Burgos-Calderón R. Cutaneous alterations in patients with chronic renal failure. Department of Dermatology, University of Puerto Rico School of Medicine, San J uan 00936-5067. Int J Dermatol.1992 Dec; 31(12):860-3.

2. Alain $\mathrm{M}, \mathrm{P}$ articular cutaneous lesions and chronic renal failure, Hospital Georges Pompidou and Broussais, Paris, France J uly 18, 2008.

3. Julia R N, Dermatologic Manifestations of Renal Disease Department of Dermatology, Virginia Commonwealth University Medical Center Updated: J an 22, 2009

4. Ponticelli $C$, Bencini $P$. The skin in chronic renal failure. In: Stewart Cameron, Alex M Davison, Jean-Pierre Grunfeld, eds. Oxford textbook of clinical nephrology. Oxford: Oxford Medical Publications: 1992:1390-4

5. Pico MR, Lugo-Somolinos A. Cutaneous alterations in patients with chronic renal failure. Int J Dermatol 1992; 31:860-3.

6. Morton CA, Lafferty M, Hau C, Henderson I, J ones $M$, Lowe J G. Pruritus and skin hydration during dialysis. Nephron Dial Transplant 1996; 11:2031-6.

7. Tawade N, Gokhale BB. Dermatologic manifestation of chronic renal failure. Indian J Dermatol Venereol Leprol 1996; 62:155-6.

8. Guptha AK, Guptha MA, Cardella CJ , Haberman HF. Cutaneous associations of chronic renal failure and dialysis. IntJ Dermatol 1986; 25:498504. Sweeney S, Cropley TG. Cutaneous changes in renal disorders. In: Freedberg IM, Eisen $A Z$, Wolff $K$, Austen KF, Goldsmith LA, Katz SI, editors. Fitzpatrick's Dermatology in general medicine. 6th ed. Mc Graw-Hill: New York; 2003. p. 1622-4. 
9. Comaish JS. Ashcroft T, Kerr DN. The pigmentation of chronic renal failure. J Am Acad Dermatol 1975; 55:215-7.

10. Singh G, Singh SJ, Chakrabarthy N, Siddharaju $\mathrm{KS}$, Prakash J C. Cutaneous manifestations of chronic renal failure. Indian J Dermatol Venereol Leprol 1989; 55:167-9.

11. Brenner BM, Lazarus J M. Chronic renal failure. In: Isselbacher KJ, Braunwald E, Wilson J D, Martin JB, Fauci AS, Kasper DL, editors. Harrison's Principles of internal medicine. 13th ed. New York: McGraw-Hill; 1994. p. 1274-81.
12. Kint A, Bussels $L$, Fernandes $M$, Ringoir $S$. Skin and nail disorders in relation to chronic renal failure. Acta Derm Venereol 1974; 54:137-40.

13. Goh GL, Phay KL. Arterio- venous shunt dermatitis in chronic renal failure patients on haemodialysis. Clin Exp Dermatol 1988; 13:1038-40. 